\title{
IdeAs
}

Idées d'Amériques

Cinéma et histoire dans les Amériques

\section{Les Jeux Olympiques 2016 à Rio de Janeiro : problèmes et défis}

\section{Vincent Dubreuil}

\section{(2) OpenEdition \\ 1 Journals}

\section{Electronic version}

URL: https://journals.openedition.org/ideas/1394

DOI: 10.4000/ideas.1394

ISSN: 1950-5701

\section{Publisher}

Institut des Amériques

\section{Electronic reference}

Vincent Dubreuil, "Les Jeux Olympiques 2016 à Rio de Janeiro : problèmes et défis", IdeAs [Online], 7 | 2016, Online since 09 June 2016, connection on 20 October 2022. URL: http:// journals.openedition.org/ideas/1394 ; DOI: https://doi.org/10.4000/ideas.1394

This text was automatically generated on 20 October 2022

\section{(c) (i) (9)}

Creative Commons - Attribution-NonCommercial-NoDerivatives 4.0 International - CC BY-NC-ND 4.0 https://creativecommons.org/licenses/by-nc-nd/4.0/ 


\title{
Les Jeux Olympiques 2016 à Rio de Janeiro : problèmes et défis
}

\author{
Vincent Dubreuil
}

1 En accueillant du 5 au 21 août 2016 les XXXI Jeux Olympiques, le Brésil devait entrer dans l'histoire à plusieurs titres. D'abord en accédant au cercle restreint de la petite vingtaine de pays ayant déjà organisé les Jeux depuis 1896, date de la première Olympiade "moderne" voulue par Pierre de Coubertin. Ensuite, comme étant seulement le deuxième pays de l'hémisphère sud à les organiser, après l'Australie à deux reprises à Melbourne en 1956 puis à Sydney en 2000. Ce sera également la première fois qu'un pays lusophone accueillera les Jeux, avec un record de plus de 10000 athlètes et plus de 200 délégations nationales prévues. Le choix par le CIO en 2009 venait effectivement consacrer l'accession du Brésil dans les pays "qui comptent" : une économie en plein essor parmi les BRICS, un modèle social de mélange des cultures et des origines, l'émergence d'une diplomatie active, un président, à l'époque, doté d'un grand prestige, autant d'arguments qui ont compté pour le choix final d'attribuer les J.0.2016 à la ville de Rio de Janeiro, et donc au Brésil.

2 L'ensemble des textes ici rassemblés font tous le constat du renversement complet de la situation du pays entre 2009 et 2016. L'optimisme et l'euphorie, ont cédé la place à la "crise" (L.A.M. da Silva) qui revêt une multitude de facettes : crise économique (chômage, inflation, dette,...), crise morale et politique (corruption, scandales financiers, impeachment), crise sociale avec une situation de violence et d'insécurité urbaines toujours préoccupante, crise sanitaire avec la recrudescence des cas de dengue et de zika propagés par le moustique Aedes aegypti. À l'heure de boucler ce dossier, on ne sait même pas qui ouvrira les J.O. en raison de la procédure de destitution en cours de l'actuelle présidente Dilma Rousseff. Deux ans après la Coupe du Monde de football, quatre ans après le sommet de l'environnement RIO+20, ce nouveau mega-event (J.Ninnin, A.Zaluar, C.Barcellos) risque donc de renvoyer au monde l'image d'un pays en proie à de graves difficultés et en plein doute.

3 Au-delà de ces considérations nationales, la réception d'une telle manifestation était aussi pour la ville de Rio de Janeiro l'occasion de renouer avec son passé de capitale, 
rôle qu'elle a cédé à Brasilia sur le plan politique et à São Paulo sur le plan économique. Ce devait être aussi l'occasion de repenser la ville, dans son rapport à l'espace, à sa nature, à ses habitants, les cariocas. Les sites olympiques, présents autour de quatre pôles dans l'agglomération ont ainsi conduit à des restructurations des quartiers, des infrastructures et des transports, aujourd'hui loin d'être achevés, contrairement aux équipements sportifs (J.Boycoff, G.Mascarenhas). La question des favelas et de leur "pacification" a été l'élément le plus médiatisé (H.Théry), l'action visant, le plus souvent, à déplacer les problèmes plus qu'à vraiment chercher à les résoudre. Finalement, la place du secteur touristique, en remettant au centre la culture et la nature exceptionnelles de la cidade maravilhosa (C. Castro), peut laisser imaginer que la ferveur et l'optimisme des Brésiliens sauront, autour de cet évènement, redonner l'espoir à une ville et à tout un peuple.

\section{AUTHOR}

\section{VINCENT DUBREUIL}

Vincent Dubreuil est Professeur de Climatologie à l'Université Rennes 2 où il dirige le laboratoire COSTEL (Climat et Occupation des Sols par Télédétection) de 2001 à 2007. Ses travaux portent sur les risques (sécheresse) et les changements climatiques en France et au Brésil de l'échelle locale (îlots de chaleur urbain) à l'échelle régionale (impact de la déforestation en Amazonie sur le climat) et utilisent de manière privilégiée les données de satellites. Il coordonne ou participe à plusieurs projets de recherches en collaboration avec le Brésil (CNRS, COFECUB, H2020,

FAPESP...). 